\title{
Relationship between physical performance and cognitive performance measures among community-dwelling older adults
}

This article was published in the following Dove Press journal:

Clinical Epidemiology

3 October 2014

Number of times this article has been viewed

\author{
Huiloo Won' \\ Devinder Kaur Ajit Singh ${ }^{2}$ \\ Normah Che Din ${ }^{3}$ \\ Manal Badrasawi ${ }^{4}$ \\ Zahara Abdul Manaf ${ }^{4}$ \\ Sin Thien Tan ${ }^{2}$ \\ Chu Chiau Tai ${ }^{2}$ \\ Suzana Shahar ${ }^{4}$
}

'Nutrition Science Program, ${ }^{2}$ Physiotherapy Program, ${ }^{3}$ Health Psychology Program, ${ }^{4}$ Dietetics Program, Faculty of Health Sciences, Universiti Kebangsaan Malaysia, Kuala Lumpur, Malaysia

Correspondence: Suzana Shahar Dietetics Programme, Faculty of Health Sciences, Universiti Kebangsaan Malaysia, Jalan Raja Muda Abdul Aziz, 50300 Kuala Lumpur, Malaysia

Tel +60392897607

Email suzana.shahar@gmail.com
Purpose: Cognitive impairment is correlated with physical function. However, the results in the literature are inconsistent with cognitive and physical performance measures. Thus, the aim of this study was to determine the association between cognitive performance and physical function among older adults.

Methods: A total of 164 older adults aged $\geq 60$ years and residing in low-cost housing areas in Kuala Lumpur, Malaysia participated in this study. Cognitive performance was measured using the Mini Mental State Examination, clock drawing test, Rey auditory verbal learning test, digit symbol test, digit span test, matrix reasoning test, and block design test. Physical performance measures were assessed using the ten step test for agility, short physical performance battery test for an overall physical function, static balance test using a Pro.Balance board, and dynamic balance using the functional reach test.

Results: There was a negative and significant correlation between agility and the digit symbol test ( $r=-0.355)$, clock drawing test $(r=-0.441)$, matrix reasoning test $(r=-0.315)$, and block design test $(r=-0.045)$. A significant positive correlation was found between dynamic balance, digit symbol test $(r=0.301)$, and matrix reasoning test $(r=0.251)$. The agility test appeared as a significant $\left(R^{2}=0.183, R^{2}=0.407, R^{2}=0.299, P<0.05\right)$ predictor of some cognitive performance measures, including the digit span test, clock drawing test, and Mini Mental State Examination.

Conclusion: These results suggest that a decline in most cognitive performance measures can be predicted by poor execution of a more demanding physical performance measure such as the ten step test for agility. It is imperative to use a more complex and cognitively demanding physical performance measure to identify the presence of an overall cognitive impairment among community-dwelling older adults. It may also be beneficial to promote more complex and cognitively challenging exercises and activities among older adults for optimal physical and cognitive function.

Keywords: cognitive performance, physical performance, older adults

\section{Introduction}

The aging population in Malaysia has significantly increased in number over the last few decades. It is imperative to perform extensive research to provide evidence-based strategies for successful aging. ${ }^{1}$ Aging affects many domains of cognitive performance. ${ }^{2}$ Even though evidence indicates that age-related cognitive decline is related with genetic factors, ${ }^{3,4}$ there is also a strong possibility that cognitive performance declines with a parallel decrease in physical performance. ${ }^{5}$ This is partly due to the common biological changes and underlying age-related decline shared by both physical and cognitive functioning. ${ }^{6}$ 
In several prospective studies, it has been demonstrated that maintenance of higher levels of physical fitness helps to protect against cognitive deterioration, even at an advanced age. ${ }^{7,8}$ Maintaining higher levels of physical performance and cardiorespiratory and aerobic fitness may help in mitigating cognitive impairments among older adults. ${ }^{9-11}$ In a study by Voss et al, ${ }^{12}$ it was reported that aerobic fitness was associated with better average accuracy and mean response time across all levels of spatial memory task among older adults. Poor physical performance among older adults may also lead to more rapid cognitive decline and early onset of dementia. ${ }^{13}$ However, the association between many cognitive measures and physical performance measures is still unclear due to methodological differences in the studies. Muscle strength was found to be associated with cognitive performance. ${ }^{14}$ Balance ability and mobility were demonstrated to be associated with cognitive performance but these physical performance measures had a sex moderated effect. ${ }^{15}$ It has also been suggested that the effect of the many physical performance measures on the different domains in cognitive performance may be the same. ${ }^{15}$

It is noteworthy that in the previous studies, a predictive physical performance measure was not included in examining the association between cognitive performance and physical performance measures. Thus, the objectives of this study were to determine the association between cognitive performance and physical performance measures that included agility, overall physical performance, and dynamic and static balance among community-dwelling older adults, and to examine whether physical performance can predict cognition in older adults. This study is part of a larger study among older adults in Malaysia (Kuala Lumpur Aging Study [KLAS]). ${ }^{16}$

\section{Methods}

A total of 164 older adults aged $\geq 60$ years and residing in low-cost housing areas, ie, Kuala Lumpur City Hall Flat Housing Area, Zone 1, Cheras, were invited to participate in this cross-sectional study using advertisements and flyers. Older adults who 1) had severe vision, hearing, and speech problems; 2) had difficulty in getting around without assistance from another person or device; 3) had difficulty in walking $6 \mathrm{~m}$; 4) had severe medical conditions and were on antipsychotics, antidepressants, hormone replacement therapy, and drugs affecting the dopaminergic system or had severe osteoarticular pathologies with functional limitations, vertebral stenosis, primitive and minor neuroradicular diseases, invalidating neurological diseases, former acute cerebral vascular events, cognitive deficit, diabetic neuropathy, Parkinson's disease and minor parkinsonism, vertigo syndromes (labyrinthine disease, dizziness), stroke, or under active therapy for life-threatening cancers; 5) were unable to be contacted or refused to participate in the study; and 6) had a Geriatric Depression Scale ${ }^{17}$ score greater than five; were excluded. Informed consent was obtained after providing both written and verbal information to the participants. Ethical approval was obtained from the Secretariat for Research and Ethics of Universiti Kebangsaan Malaysia (KLAS-NN-135-2011). Participants gathered at respective community centers and were interviewed for sociodemographic and neuropsychological status. Then, physical performance was assessed by trained final year physiotherapist undergraduates.

\section{Demographic information and physical assessment}

Age, sex, ethnicity, marital status, education level, and medical conditions were obtained using a pretested questionnaire. The presence of hypertension, diabetes, stroke, heart disease, asthma, osteoporosis, hip fracture, and arthritis were defined as a self-reported condition based on diagnosis by the participant's physician. Functional status (instrumental activities of daily living $)^{18}$ was also obtained using pretested questionnaires.

\section{Physical performance measures}

Agility was measured using the ten step test (TST),${ }^{19}$ in which participants were asked to step one foot up and down onto a $10 \mathrm{~cm}$ height block followed by the other foot, as fast as possible. The time taken by the participant to perform ten repetitions was recorded. The shorter the time the participant used to complete the ten repetitions, the better their agility. TST has been reported to be highly reliable $(r=0.960)$ in individuals ranging in age from 20-99 years. ${ }^{19}$ TST, which includes quickness and repetition, is suitable to use for agility testing.

The short physical performance battery $(\mathrm{SPPB})^{20}$ was used to measure physical performance. SPPB consists of three tests that include walking speed, chair stands, and standing balance. Each test is scored from zero (inability to complete the task) to four (highest level of performance). The sum of the score (zero to 12) was used as a measurement of level of physical performance. In the standing balance test, participants were required to maintain tandem, semi-tandem, and side-by-side standing for 10 seconds. For the timed chair test, participants were instructed to sit and stand five times as quickly as possible on a straight back chair with their arms crossed over their chest and back leaning on the chair. In the 
walking speed test, participants were instructed to walk a standard distance of a 12 foot pathway ( 2 feet of acceleration, 8 feet of usual speed steady walk, and 2 feet of deceleration). Participants were allowed to use their walking aids in this test and walk at their usual pace. High reliability $(r=0.89)$ was reported for SPPB in a population aged 64-75 years. ${ }^{21}$

Static balance was tested using a Pro.Balance board (Lab Rehab Pte Ltd, Singapore), which has an intraclass correlation coefficient of $r=0.92 .{ }^{22,23}$ Participants were requested to stand on the Pro.Balance board with their eyes open while maintaining their balance for 30 seconds. Overall balance performance was calculated using the Pro.Balance software. This method has been used among older adults in a previous study. ${ }^{24}$

Dynamic balance was measured using the functional reach test (FRT). ${ }^{25}$ In FRT, participants were asked to stand barefooted while maintaining an upright position and to reach forward with an outstretched arm without moving their feet. The distance of reaching was represented by the difference between the starting and ending position of the third knuckle. Participants who were able to reach farther indicated better dynamic balance. High reliability $(r=0.92)$ using FRT was reported in an elderly population aged 69-104 years. ${ }^{26}$

\section{Cognitive performance tests}

Cognitive function was assessed using seven cognitive domains: global cognitive function (Mini Mental State Examination [MMSE]), ${ }^{27}$ executive control function (the clock drawing test), ${ }^{28}$ verbal memory (Rey auditory verbal learning test [RAVLT]), ${ }^{29}$ and subtests of Wechsler Adult Intelligent Scale III, ${ }^{30}$ ie, digit symbol, digit span, matrix reasoning, and block design. Depression was assessed using the Geriatric Depression Scale questionnaire. ${ }^{31}$

MMSE is composed of 13 components which are divided into five sections: orientation, registration, attention and calculation, recall, and language and copying. ${ }^{27}$ The maximum possible score is 30 points. Cronbach's $\alpha$ of 0.76 was obtained from a Malaysian elderly population aged 57-75 years old. ${ }^{32}$ In the clock drawing test, participants were given blank paper and asked to "draw a clock that says 1:45" and "set the numbers and face of the clock so that a child can read them." ${ }^{28}$ The score ranged from zero (poorest performance) to 15 (best performance). A high degree of reliability $(r=0.94)$ was reported in elderly subjects. ${ }^{28}$

RAVLT was evaluated by giving five trials to participants to learn a 15-word list and then asking them to recall the words after a brief interval (immediate recall) and a 20-minute delay (delayed recall). ${ }^{29}$ The number of words correctly recalled at each time point was recorded. The score ranged from zero (poorest performance) to 90 (best performance). Cronbach's $\alpha$ of 0.85 was reported in elderly aged $\geq 60$ years. ${ }^{33}$ The digit symbol test, with an intraclass correlation coefficient of $0.846,{ }^{34}$ was used to assess psychomotor performance, attention, and ability to remember and operate on complex symbols. ${ }^{30}$ Participants were given paper and a pencil and required to copy as many novel symbols corresponding to numbers as possible in 120 seconds. The score ranged from zero (poorest performance) to 133 (best performance).

In the digit span test, with an intraclass correlation coefficient of $0.78,{ }^{30}$ the participants were given a list of digits and asked to repeat it back. If the participants could repeat a two-digit list, a three-digit list, four-digit list, and so on was given until the participants failed to repeat two listed digits continuously. ${ }^{30,35}$ The score ranged from zero (poorest performance) to 30 (best performance). The matrix reasoning test (test-retest reliability of $r=0.77$ ) was carried out by giving participants an incomplete matrix and asking them to select the response option that completed the matrix. ${ }^{36}$ The score ranged from zero (poorest performance) to 26 (best performance). In the block design test (test-retest reliability of $r=0.82$ ), participants were given a picture and asked to use red and white blocks to recreate the design. ${ }^{30,37}$ The score ranged from zero (poorest performance) to 68 (best performance).

\section{Statistical analysis}

All statistical analyses were performed using $\mathrm{SPSS}^{\circledR}$ version 20.0 (IBM Corporation, Armonk, NY, USA). Descriptive analyses of the demographic characteristics of the participants were expressed as mean \pm standard deviation (SD) or percentage. The Kolmogorov-Smirnov test was performed to examine the normality of data $(P>0.05)$. Raw scores of the digit span test, digit symbol test, block design test, and matrix reasoning test were converted into scale scores to reconstruct the original distribution of raw scores for each age group. Pearson's correlation coefficients between physical and cognitive function tests were determined. Point-biserial correlation was used for medical conditions, which was dichotomized as $1=$ present and $0=$ not present. Variables found to be significant using univariate analysis at $P<0.05$ were analyzed using multiple hierarchical regression while controlling for the influential demographics (age, sex, race, and education level) and medical conditions (associated with neurocognitive or physical function: hypertension, hyperlipidemia, diabetes, stroke, heart disease, asthma, osteoporosis, hip fracture, and arthritis diagnosed by a physician). An unstandardized coefficient was used in the regression - for every unit (score) change 
in the physical performance test, cognitive function changed by $\mathrm{X}$ units. Physical performance measures were defined as the independent variable, and cognitive performance tests were defined as the dependent variable. The number of cognitive performance test scores that were influenced by each of the four physical performance measure scores were determined.

\section{Results}

Table 1 shows the baseline characteristics of participants. A total of 164 participants participated in the study aged from 69-80 years, with a mean age of $66 \pm 4.6$ years. The majority of the participants were women $(65.6 \%)$ and the mean $\pm \mathrm{SD}$ number of education years was $11.9 \pm 0.3$ years. Most participants were generally healthy with a very low mean Geriatric Depression Scale score (mean $\pm \mathrm{SD}, 2.6 \pm 2.1$ ), indicating no depression among the participants.

Table I Baseline characteristics of participants $(n=164)$

\begin{tabular}{|c|c|}
\hline Characteristics & Mean \pm SD or $\%$ \\
\hline \multicolumn{2}{|l|}{ Demographic data } \\
\hline Age, years & $66.0 \pm 4.6$ \\
\hline Female & $66.5 \%$ \\
\hline Education, years & $11.9 \pm 0.3$ \\
\hline \multicolumn{2}{|l|}{ Cognitive function } \\
\hline MMSE, score ${ }^{27}$ & $25.9 \pm 3.4$ \\
\hline CLOXI, score ${ }^{28}$ & $6.9 \pm 2.2$ \\
\hline Total RAVLT, score ${ }^{29}$ & $41.6 \pm 13.9$ \\
\hline Digit symbol, score ${ }^{30}$ & $5.5 \pm 2.7$ \\
\hline Digit span, score ${ }^{30}$ & $8.4 \pm 2.4$ \\
\hline Matrix reasoning, score $\mathrm{e}^{30}$ & $8.0 \pm 3.3$ \\
\hline Block design, score ${ }^{30}$ & $6.4 \pm 3.3$ \\
\hline \multicolumn{2}{|l|}{ Psychological function } \\
\hline GDS, score ${ }^{31}$ & $2.6 \pm 2.1$ \\
\hline \multicolumn{2}{|l|}{ Physical function } \\
\hline TST, seconds ${ }^{19}$ & $17.1 \pm 3.6$ \\
\hline SPPB, score ${ }^{20}$ & $11.7 \pm 0.6$ \\
\hline Pro.Balance board, seconds ${ }^{22}$ & $2.2 \pm 1.0$ \\
\hline $\mathrm{FRT}, \mathrm{cm}^{25}$ & $29.5 \pm 5.5$ \\
\hline IADL, score ${ }^{18}$ & $13.4 \pm 1.2$ \\
\hline \multicolumn{2}{|l|}{ Medical conditions } \\
\hline Hypertension & $58.5 \%$ \\
\hline Hyperlipidemia & $53.7 \%$ \\
\hline Diabetes & $31.7 \%$ \\
\hline Stroke & $1.8 \%$ \\
\hline Heart attack & $4.9 \%$ \\
\hline Heart failure & $3.0 \%$ \\
\hline Asthma & $4.3 \%$ \\
\hline Osteoporosis & $1.8 \%$ \\
\hline Hip fracture & $0.6 \%$ \\
\hline Arthritis & $26.2 \%$ \\
\hline
\end{tabular}

Abbreviations: CLOXI, clock drawing test; FRT, functional reach test; GDS, Geriatric Depression Scale; IADL, instrumental activities of daily living; MMSE, Mini Mental State Examination; RAVLT, Rey auditory verbal learning test; SD, standard deviation; SPPB, short physical performance battery; TST, ten step test.
There was a negative and significant $(P<0.01)$ correlation between TST and the digit span test, digit symbol test, clock drawing test, matrix reasoning, RAVLT, and MMSE based on univariate Pearson's correlation test, with a correlation coefficient ranging from -0.315 to -0.441 (Table 2 ). A positive and significant correlation was found between dynamic balance and the digit symbol test $(r=0.301, P<0.01)$, clock drawing test ( $r=0.201, P<0.05)$, and matrix reasoning test $(r=0.251, P<0.05)$. A similar trend was noted for the SPPB and digit span test $(r=0.265, P<0.01)$, digit symbol test ( $r=0.246, P<0.05)$, and clock drawing test $(r=289, P<0.01)$, which were also strongly positive and significant. However, the relationship between static balance and all cognitive measures was not significant.

Further analysis using the multiple hierarchical regression model was performed to examine the physical performance measures that seemed to be predictors for cognitive performance (Table 3). Agility as assessed using TST was detected as a significant predictor of the digit span test $\left(R^{2}=0.183, P<0.05\right)$, clock drawing test $\left(R^{2}=0.299, P<0.01\right)$, and MMSE $\left(R^{2}=0.407, P<0.05\right)$ after adjusting for age, sex, education, and medical condition. No significant association with the block design test, digit symbol test, matrix reasoning test, and RAVLT was detected with all physical measures (agility, physical performance, dynamic balance, and static balance).

\section{Discussion}

The main objective of this study was to determine the association between cognitive and physical performance measures among community-dwelling older adults. To the best of the authors' knowledge, this is the first study to report TST - an agility test - as the strongest predictor for cognitive performance that is related to global cognitive function, executive control function, verbal memory, processing speed, working memory, and perceptual organization.

TST has been used to measure agility among older adults. ${ }^{38}$ Agility represents the capability to accurately alter position and direction as fast as possible without losing balance. ${ }^{39}$ It can be argued that TST is a complex movement whereby one will need quick visual neuromotor actions to place each foot repetitively, alternately, and precisely ten times on a stool while maintaining equilibrium. It is presumed that to perform TST one must have adequate mobility, strength, endurance, speed, precision, proprioception, balance, and executive ability. Executive ability can be defined as the execution of a specific goal-orientated composite task that requires planning, monitoring, and execution. ${ }^{40}$ Thus, TST 
Table 2 Correlation coefficients of cognitive and physical function tests

\begin{tabular}{|c|c|c|c|c|c|c|c|}
\hline \multirow[t]{2}{*}{ Factors } & \multicolumn{7}{|c|}{ Cognitive functions } \\
\hline & Digit span & Digit symbol & BD & MR & CLOXI & MMSE & RAVLT total \\
\hline \multicolumn{8}{|l|}{ Sociodemographic } \\
\hline Age & 0.085 & 0.021 & $0.438^{* *}$ & 0.084 & $-0.257 * *$ & -0.156 & $-0.287^{* *}$ \\
\hline Sex & $-0.195^{* *}$ & $-0.285^{* *}$ & $-0.336 * *$ & $-0.301 * *$ & -0.150 & -0.114 & 0.048 \\
\hline Education years & $0.232 *$ & $0.370 * *$ & 0.189 & $0.296 * *$ & $0.270 * *$ & $0.560 * *$ & $0.24 I^{*}$ \\
\hline \multicolumn{8}{|l|}{ Medical conditions } \\
\hline Hypertension & -0.114 & -0.115 & -0.076 & -0.054 & $-0.189 *$ & -0.073 & $-0.195 * *$ \\
\hline Hyperlipidemia & 0.033 & 0.002 & -0.037 & -0.008 & 0.095 & 0.119 & -0.017 \\
\hline Diabetes & $-0.177^{*}$ & $-0.175^{*}$ & -0.142 & -0.058 & $-0.172^{*}$ & -0.070 & $-0.183^{*}$ \\
\hline Stroke & -0.077 & -0.100 & -0.076 & $-0.173 *$ & -0.121 & -0.051 & -0.030 \\
\hline Heart attack & -0.038 & 0.131 & 0.020 & 0.008 & 0.055 & -0.016 & 0.017 \\
\hline Heart failure & 0.028 & 0.139 & 0.119 & $0.163 *$ & 0.078 & 0.110 & $0.151 *$ \\
\hline Asthma & -0.029 & -0.022 & 0.013 & 0.020 & -0.083 & -0.071 & -0.125 \\
\hline Osteoporosis & 0.038 & -0.016 & -0.005 & -0.099 & 0.075 & -0.071 & 0.107 \\
\hline Hip fracture & 0.079 & 0.046 & -0.140 & $-0.08 \mathrm{I}$ & -0.084 & -0.091 & -0.028 \\
\hline Arthritis & 0.018 & -0.036 & 0.004 & -0.023 & -0.091 & -0.071 & -0.005 \\
\hline \multicolumn{8}{|l|}{ Physical functioning } \\
\hline $\mathrm{TST}^{19}$ & $-0.355^{* *}$ & $-0.355^{* *}$ & -0.045 & $-0.315 * *$ & $-0.44 I^{* *}$ & $-0.374 * *$ & $-0.352^{* *}$ \\
\hline $\mathrm{FRT}^{25}$ & 0.118 & $0.301 * *$ & 0.107 & $0.251 *$ & $0.201 *$ & 0.168 & 0.142 \\
\hline Pro.Balance ${ }^{22}$ & -0.052 & -0.023 & 0.081 & 0.072 & -0.077 & -0.022 & -0.070 \\
\hline $\mathrm{SPPB}^{20}$ & $0.265^{* *}$ & $0.246 *$ & 0.059 & 0.123 & $0.289 * *$ & 0.134 & 0.155 \\
\hline $\mathrm{IADL}^{18}$ & 0.022 & 0.122 & 0.128 & 0.062 & 0.130 & $0.241 * *$ & 0.111 \\
\hline
\end{tabular}

Notes: $* P<0.05 ; * * P<0.01$.

Abbreviations: BD, block design; CLOXI, clock drawing test; FRT, functional reach test; IADL, instrumental activities of daily living; MMSE, Mini Mental State Examination; MR, matrix reasoning; RAVLT, Rey auditory verbal learning test; SPPB, short physical performance battery; TST, ten step test.

may have appeared as a predictor for cognitive performance, as shown in this study.

Significant correlation was found between dynamic balance - measured using FRT - and cognitive measures, including the digit symbol test, matrix reasoning test, and clock drawing test, among community-dwelling older adults in this study. Similarly, in a previous study among 50 healthy participants using FRT to measure physical performance, a decline in both physical and cognitive performance was reported. ${ }^{41}$ Dynamic balance ability is one of the key prerequisites in performing activities of daily living. A Canadian study of health and aging reported that FRT score was higher in participants with higher activities of daily living score. ${ }^{26}$

Among all cognitive performance being investigated, a global cognitive performance measured using MMSE was most influenced by physical function $\left(\beta=-0.065, R^{2}=0.338\right)$. This is in agreement with a cross-sectional study among 207 participants. MMSE is a complex tool that can be used to systematically and comprehensively assess mental health. ${ }^{27}$ A study on an elderly population aged 85 years old reported that MMSE was significantly associated with physical fitness measurements. ${ }^{42}$ A study on participants aged 75-99 years with seated range-of-motion exercises and strength training using elastic resistance bands and soft weights reported that MMSE scores of the participants increased by 3.1 after 1 year of exercise.

Multiple hierarchical regression - a type of multiple comparison model - was performed to find the best predictors of cognitive function in the present study. This model controls the potential effects of other variables such as age, sex, education, and medical condition. Multiple comparisons increased the potential for type I errors, which occur when statistical tests are performed repeatedly. When many comparisons were made among the variables, there was a chance for the $P$-value, which is related with each individual comparison, to be underestimated. This multiple comparisons problem was solved using the multiple hierarchical model to carry out partial pooling, eg, shifting estimates toward each other.

There are several strengths in this study. Firstly, performance-based measures for agility, overall physical performance, and balance were used. These minimized potential bias - either referral bias or bias regarding emerging cognitive impairment, as the study involved older adults. Secondly, the degree and significance of association between each of the physical performance measures and cognitive performance were examined. The limitation in this study was that the study population consisted of community-dwelling older adults with a lower level of financial status. Hence, it is not clear 
Table 3 Influence of physical function on cognitive function

\begin{tabular}{|c|c|c|c|c|}
\hline $\begin{array}{l}\text { Cognitive } \\
\text { outcome }\end{array}$ & Variable & $\beta(95 \% \mathrm{Cl})$ & $R^{2}$ & $\Delta R^{2}$ \\
\hline \multirow[t]{10}{*}{ Digit span ${ }^{30}$} & Step I & & $0.125^{* *}$ & $0.125^{* *}$ \\
\hline & Sex & $-0.591(-1.60,0.41)$ & & \\
\hline & Education & $0.707 *(0.18,1.23)$ & & \\
\hline & Diabetes & $-0.654(-1.58,0.27)$ & & \\
\hline & Step 2 & & $0.183^{* *}$ & $0.058 *$ \\
\hline & Sex & $-0.447(-1.44,0.54)$ & & \\
\hline & Education & $0.447(-0.11,1.00)$ & & \\
\hline & Diabetes & $-0.420(-1.35,0.51)$ & & \\
\hline & TST $^{19}$ & $-0.148^{*}(-0.28,-0.02)$ & & \\
\hline & $\mathrm{SPPB}^{20}$ & $0.27 \mathrm{I}(-0.48, \mathrm{I} .02)$ & & \\
\hline Digit & Step I & & $0.323 * * *$ & $0.323 * * *$ \\
\hline \multirow[t]{10}{*}{ symbol $^{30}$} & Sex & $-2.062^{*}(-3.22,-0.90)$ & & \\
\hline & Education & I.I24* $(0.53,1.72)$ & & \\
\hline & Diabetes & $-0.818(-1.87,0.23)$ & & \\
\hline & Step 2 & & $0.346 * * *$ & 0.023 \\
\hline & Sex & $-1.873^{*}(-3.08,-0.66)$ & & \\
\hline & Education & $0.934 *(0.29,1.58)$ & & \\
\hline & Diabetes & $-0.612(-1.70,0.47)$ & & \\
\hline & TST $^{19}$ & $-0.088(-0.25,0.08)$ & & \\
\hline & $\mathrm{SPPB}^{20}$ & $0.228(-0.89,1.34)$ & & \\
\hline & $\mathrm{FRT}^{25}$ & $0.30(-0.08,0.14)$ & & \\
\hline Block & Step I & & $0.270 * * *$ & $0.270 * * *$ \\
\hline \multirow[t]{2}{*}{ design ${ }^{30}$} & Age & $0.250 *(0.13,0.37)$ & & \\
\hline & Sex & $-2.108^{*}(-3.28,-0.93)$ & & \\
\hline Matrix & Step I & & $0.190 * *$ & $0.190 * *$ \\
\hline \multirow[t]{11}{*}{ reasoning $g^{30}$} & Sex & $-1.095(-2.42,0.23)$ & & \\
\hline & Education & $1.086 *(0.40,1.77)$ & & \\
\hline & Stroke & $-2.084(-5.92,1.74)$ & & \\
\hline & Heart failure & $0.554(-2.23,3.34)$ & & \\
\hline & Step 2 & & $0.229 * *$ & 0.052 \\
\hline & Sex & $-0.850(-2.22,0.52)$ & & \\
\hline & Education & $0.778 *(0.03,1.53)$ & & \\
\hline & Stroke & $-2.027(-5.8 \mathrm{I}, \mathrm{I} .75)$ & & \\
\hline & Heart failure & $0.919(-1.94,3.78)$ & & \\
\hline & TST $^{19}$ & $-0.152(-0.34,0.04)$ & & \\
\hline & $\mathrm{FRT}^{25}$ & $0.042(-0.07,0.16)$ & & \\
\hline \multirow[t]{13}{*}{ CLOXI ${ }^{28}$} & Step I & & $0.221 * * *$ & $0.221 * * * *$ \\
\hline & Age & $-0.119 *(-0.20,-0.04)$ & & \\
\hline & Education & $0.695 *(0.25,1.14)$ & & \\
\hline & Hypertension & $-0.597(-1.45,0.26)$ & & \\
\hline & Diabetes & $-0.392(-1.28,0.50)$ & & \\
\hline & Step 2 & & $0.299 * * *$ & $0.078 *$ \\
\hline & Age & $-0.083^{*}(-0.16,0.00)$ & & \\
\hline & Education & $0.419(-0.08,0.87)$ & & \\
\hline & Hypertension & $-0.348(-1.21,0.48)$ & & \\
\hline & Diabetes & $-0.275(-1.13,0.60)$ & & \\
\hline & TST $^{19}$ & $-0.169 *(-0.28,-0.04)$ & & \\
\hline & SPPB $^{20}$ & $0.140(-0.66,0.74)$ & & \\
\hline & $\mathrm{FRT}^{25}$ & $0.030(-0.05,0.11)$ & & \\
\hline RAVLT & Step I & & $0.283^{* * *}$ & $0.283^{* * *}$ \\
\hline total $^{29}$ & Age & $-1.089 *(-1.62,-0.56)$ & & \\
\hline
\end{tabular}

(Continued)
Table 3 (Continued)

\begin{tabular}{|c|c|c|c|c|}
\hline $\begin{array}{l}\text { Cognitive } \\
\text { outcome }\end{array}$ & Variable & $\beta(95 \% \mathrm{Cl})$ & $R^{2}$ & $\Delta R^{2}$ \\
\hline & Education & 3.878* $(0.89,6.87)$ & & \\
\hline & Hypertension & $-3.573(-9.15,2.01)$ & & \\
\hline & Diabetes & $-3.722(-9.48,2.04)$ & & \\
\hline & Heart failure & $10.938(-1.69,23.56)$ & & \\
\hline & Step 2 & & $0.310 * * *$ & 0.028 \\
\hline & Age & $-0.949 *(-1.49,-0.4 I)$ & & \\
\hline & Education & $2.638(-0.59,5.86)$ & & \\
\hline & Hypertension & $-2.640(-8.23,2.95)$ & & \\
\hline & Diabetes & $-3.358(-9.05,2.33)$ & & \\
\hline & Heart failure & $12.377(0.16,24.92)$ & & \\
\hline & TST $^{19}$ & $-0.742(-1.52,0.04)$ & & \\
\hline \multirow[t]{6}{*}{$\mathrm{MMSE}^{27}$} & Step I & & $0.323^{* *}$ & $0.323 * *$ \\
\hline & Education & $4.366 *(1.31,7.42)$ & & \\
\hline & Step 2 & & $0.407^{* * * *}$ & $0.084 * *$ \\
\hline & Education & $2.067^{*}(-1 .|8,5.3|)$ & & \\
\hline & TST $^{19}$ & $-1.021 *(-1.80,-0.25)$ & & \\
\hline & $\mathrm{IADL}^{18}$ & $2.192 *(-0.21,4.59)$ & & \\
\hline
\end{tabular}

Notes: $* P<0.05 ; * * P<0.01 ; * * * P<0.001$ using multiple hierarchical regression. The control variables were: age, sex, race, education level, hypertension, hyperlipidemia, diabetes, stroke, heart disease, asthma, osteoporosis, hip fracture, and arthritis.

Abbreviations: $\beta$, standardized regression coefficient; CLOXI, clock drawing test; $\mathrm{Cl}$, confidence interval; $\Delta R^{2}$, change in $R^{2}$; FRT, functional reach test; IADL, instrumental activities of daily living; MMSE, Mini Mental State Examination; RAVLT, Rey auditory verbal learning test; SPPB, short physical performance battery; TST, ten step test.

that comparable results could be obtained among older adults from a different socioeconomic background. Also, the high mean scores on cognitive performance reflect a ceiling effect, which might be caused by the small number of participants. Older participants might have felt too fatigued to complete all of the physical tests. However, rest was provided in between all of the physical tests. The analysis did not include smoking as a confounding factor, which might have affected the physical and cognitive performance.

\section{Conclusion}

This study provides evidence that a more demanding physical performance measure such as the TST is a predictor for cognitive performance measure among community-dwelling older adults. The results of this study suggest that it is imperative to use a more complex and cognitively demanding physical performance measure to identify the presence of an overall cognitive impairment among community-dwelling older adults. It may also be beneficial to promote more complex and cognitively challenging exercises and activities among older adults for optimal physical and cognitive function. 
Further research, such as a longitudinal study, is needed for inferences of causation.

\section{Acknowledgments}

The study was funded by UKM GUP 2011-130, UKM AP 2011-27, and LRGS/BU/2012/UKM-UKM/K/01. The authors thank the participants, field workers, and co-researchers involved in this study.

\section{Disclosure}

The authors report no conflicts of interest in this work.

\section{References}

1. Hamid TA, Momtaz YA, Ibrahim R. Predictors and prevalence of successful aging among older Malaysians. Gerontology. 2011;58(4): 366-370.

2. Hedden T, Gabrieli JD. Insights into the ageing mind: a view from cognitive neuroscience. Nat Rev Neurosci. 2004;5(2):87-96.

3. Benedict C, Jacobsson JA, Ronnemaa E, et al. The fat mass and obesity gene is linked to reduced verbal fluency in overweight and obese elderly men. Neurobiol Aging. 2011;32(6):1159. e1-e5.

4. Keller L, Xu W, Wang HX, Winblad B, Fratiglioni L, Graff C. The obesity related gene, FTO, interacts with APOE, and is associated with Alzheimer's disease risk: a prospective cohort study. J Alzheimers Dis. 2011;23(3):461-469.

5. Bruce-Keller AJ, Brouillette RM, Tudor-Locke C, et al. Relationship between cognitive domains, physical performance, and gait in elderly and demented subjects. J Alzheimers Dis. 2012;30(4):899-908.

6. Clouston SA, Brewster P, Kuh D, et al. The dynamic relationship between physical function and cognition in longitudinal aging cohorts. Epidemiol Rev. 2013;35(1):33-50.

7. Netz Y, Dwolatzky T, Zinker Y, Argov E, Agmon R. Aerobic fitness and multidomain cognitive function in advanced age. Int Psychogeriatr. 2011;23(1):114-124.

8. Garcia S, Alosco ML, Spitznagel MB, et al. Cardiovascular fitness associated with cognitive performance in heart failure patients enrolled in cardiac rehabilitation. BMC Cardiovasc Disord. 2013;1 $3: 29$.

9. Komulainen P, Kivipelto M, Lakka TA, et al. Exercise, fitness, and cognition - a randomised controlled trial in older individuals: the DR's EXTRA study. Eur Geriatr Med. 2010;1(5):266-272.

10. Kramer AF, Erickson KI. Capitalizing on cortical plasticity: influence of physical activity on cognition and brain function. Trends Cogn Sci. 2007;11(8):342-348.

11. Pereira AC, Huddleston DE, Brickman AM, et al. An in vivo correlate of exercise-induced neurogenesis in the adult dentate gyrus. Proc Natl Acad Sci U S A. 2007;104(13):5638-5643.

12. Voss MW, Erickson KI, Prakash RS, et al. Functional connectivity: a source of variance in the association between cardiorespiratory fitness and cognition? Neuropsychologia. 2010;48(5):1394-1406.

13. Wang L, Larson EB, Bowen JD, van Belle G. Performance-based physical function and future dementia in older people. Arch Intern Med. 2006;166(10):1115-1120.

14. Alfaro-Acha A, Al Snih S, Raji MA, Kuo YF, Markides KS, Ottenbacher KJ. Handgrip strength and cognitive decline in older Mexican Americans. J Gerontol A Biol Sci Med Sci. 2006;61(8):859-865.

15. Blankevoort CG, Scherder EJ, Wieling MB, et al. Physical predictors of cognitive performance in healthy older adults: a cross-sectional analysis. PloS One. 2013;8(7):e70799.

16. Universiti Kebangsaan Malaysia. Final report: Kuala Lumpur Aging Study; 2014.
17. Almeida OP, Almeida SA. 1999. Short versions of the geriatric depression scale: a study of their validity for the diagnosis of a major depressive episode according to ICD-10 and DSM-IV. Int J Geriatr Psychiatry. 1999;14(10):858-865.

18. Prowell LM, Brody EM. Assessment of older people: self-maintaining and instrumental activities of daily living. Gerontologist. 1969;9(3): $179-186$.

19. Miyamoto K, Takebayashi H, Takimoto K, Miyamoto S, Morioka S, Yagi F. A new simple performance test focused on agility in elderly people: the ten step test. Gerontology. 2008;54(6):365-372.

20. Guralnik JM, Simonsick EM, Ferrucci L, et al. A short physical performance battery assessing lower extremity function: association with self-reported disability and prediction of mortality and nursing home admission. J Gerontol. 1994;49(2):M85-M94.

21. Freire AN, Guerra RO, Alvarado B, Guralnik JM, Zunzunegui MV. Validity and reliability of the short physical performance battery in two diverse older adult populations in Quebec and Brazil. J Aging Health. 2012;24(5):863-878.

22. Ang W, Tan UX, Tan H, et al. Design and development of a novel balancer with variable difficulty for training and evaluation. Disabil Rehabil Assist Technol. 2008;3(6):325-331.

23. Koh K, Linda W. Reliability and validity of Pro.Balance. Paper presented at: Singapore Physiotherapy Association's 7th National Congress; May 16-17, 2009; Singapore.

24. Singh DK, Rajaratnam BS, Palaniswamy V, Raman VP, Bong PS, Pearson H. Effects of balance-focused interactive games compared to therapeutic balance classes for older women. Climacteric. 2012;16(1): 141-146.

25. Duncan PW, Weiner DK, Chandler J, Studenski S. Functional reach: a new clinical measure of balance. J Gerontol. 1990;45(6):M192-M197.

26. Rockwood K, Awalt E, Carver D, MacKnight C. Feasibility and measurement properties of the functional reach and the timed up and go tests in the Canadian study of health and aging. J Gerontol A Biol Sci Med Sci. 2000;55(2):M70-M73.

27. Folstein MF, Folstein SE, McHugh PR. "Mini-Mental State": a practical method for grading the cognitive state of patients for the clinician. J Psychiatr Res. 1975;12(3):189-198.

28. Royall DR, Cordes JA, Polk M. CLOX: an executive clock drawing task. J Neurol Neurosurg Psychiatry. 1998;64(5):588-594.

29. Schmidt M. Rey Auditory Verbal Learning Test: A Handbook. Los Angeles, CA: Western Psychological Services; 1996.

30. Wechsler D. WAIS-III Administration and Scoring Manual. San Antonio, TX: The Psychological Corporation; 1997.

31. Yesavage JA, Sheikh JI. 9/Geriatric Depression Scale (GDS) recent evidence and development of a shorter violence. Clin Gerontol. 1986;5(1-2):165-173.

32. Ibrahim NM, Shohaimi S, Chong HT, et al. Validation study of the Mini-Mental State Examination in a Malay-speaking elderly population in Malaysia. Dement Geriatr Cogn Disord. 2009;27(3):247-253.

33. Malloy-Diniz LF, Lasmar VA, Gazinelli Lde S, Fuentes D, Salgado JV. The Rey auditory-verbal learning test: applicability for the Brazilian elderly population. Rev Bras Psiquiatr. 2007;29(4):324-329.

34. Gonzalez-Blanch C, Perez-Iglesias R, Rodriguez-Sanchez JM, et al. A digit symbol coding task as a screening instrument for cognitive impairment in first-episode psychosis. Arch Clin Neuropsychol. 2011;26(1):48-58.

35. Cullum CM, Weiner MF, Gehrmann HR, Hynan LS. Feasibility of telecognitive assessment in dementia. Assessment. 2006;13(4):385-390.

36. Mani TM, Bedwell JS, Miller LS. Age-related decrements in performance on a brief continuous performance test. Arch Clin Neuropsychol. 2005;20(5):575-586.

37. Dikmen SS, Heaton RK, Grant I, Temkin NR. Test-retest reliability and practice effects of expanded Halstead-Reitan neuropsychological test battery. J Int Neuropsychol Soc. 1999;5(4):346-356.

38. Miller DI, Taler V, Davidson PS, Messier C. Measuring the impact of exercise on cognitive aging: methodological issues. Neurobiol Aging. 2012;33(3):622. e29-e43. 
39. Sheppard JM, Young WB. Agility literature review: classifications, training, and testing. J Sports Sci. 2006;24(9):919-932.

40. Royall DR, Lauterbach EC, Cummings JL, et al. Executive control function: a review of its promise and challenges for clinical research. A report from the Committee on Research of the American Neuropsychiatric Association. J Neuropsychiatry Clin Neurosci. 2002;14(4):377-405.
41. Costarella M, Monteleone L, Steindler R, Zuccaro SM. Decline of physical and cognitive conditions in the elderly measured through the functional reach test and the Mini-Mental State Examination. Arch Gerontol Geriatr. 2010;50(3):332-337.

42. Takata Y, Ansai T, Soh I, et al. Physical fitness and cognitive function in an 85-year-old community-dwelling population. Gerontology. 2008;54(6):354-360.

\section{Publish your work in this journal}

Clinical Epidemiology is an international, peer-reviewed, open access journal focusing on disease and drug epidemiology, identification of risk factors and screening procedures to develop optimal preventative initiatives and programs. Specific topics include: diagnosis, prognosis, treatment, screening, prevention, risk factor modification, systematic

Submit your manuscript here: http://www.dovepress.com/clinical-epidemiology-journal

\section{Dovepress}

reviews, risk \& safety of medical interventions, epidemiology \& biostatical methods, evaluation of guidelines, translational medicine, health policies \& economic evaluations. The manuscript management system is completely online and includes a very quick and fair peer-review system, which is all easy to use. 